\title{
The Bali Fintech Agenda
}




\section{INTERNATIONAL MONETARY FUND}

\section{IMF POLICY PAPER}

\section{THE BALI FINTECH AGENDA}

October 2018

IMF staff regularly produces papers proposing new IMF policies, exploring options for reform, or reviewing existing IMF policies and operations. The following documents have been released and are included in this package:

- A Press Release summarizing the views of the Executive Board as expressed during its September 7, 2018 consideration of the policy report.

- The Policy Report, prepared jointly by IMF and World Bank staff and completed on August 7, 2018 for the Executive Board's consideration on September 7, 2018.

The IMF's transparency policy allows for the deletion of market-sensitive information and premature disclosure of the authorities' policy intentions in published staff reports and other documents.

Electronic copies of IMF Policy Papers are available to the public from http://www.imf.org/external/pp/ppindex.aspx

\section{International Monetary Fund Washington DC}


Press Release No. 18/388

FOR IMMEDIATE RELEASE

October 11,2018
International Monetary Fund

Washington, D.C. 20431 USA

\section{The Bali Fintech Agenda: A Blueprint for Successfully Harnessing Fintech's Opportunities}

The International Monetary Fund and the World Bank Group today launched the Bali Fintech Agenda, a set of 12 policy elements aimed at helping member countries to harness the benefits and opportunities of rapid advances in financial technology that are transforming the provision of banking services, while at the same time managing the inherent risks.

The Agenda proposes a framework of high-level issues that countries should consider in their own domestic policy discussions and aims to guide staff from the two institutions in their own work and dialogue with national authorities. The 12 elements (see table) were distilled from members' own experiences and cover topics relating broadly to enabling fintech; ensuring financial sector resilience; addressing risks; and promoting international cooperation.

"There are an estimated 1.7 billion adults in the world without access to financial services," said IMF Managing Director Christine Lagarde. "Fintech can have a major social and economic impact for them and across the membership in general. All countries are trying to reap these benefits, while also mitigating the risks. We need greater international cooperation to achieve that, and to make sure the fintech revolution benefits the many and not just the few. This Agenda provides a useful framework for countries to assess their policy options and adapt them to their own circumstances and priorities.

"The Bali Fintech Agenda provides a framework to support the Sustainable Development Goals, particularly in low-income countries, where access to financial services is low," World Bank Group President Jim Yong Kim said. "Countries are demanding deeper access to financial markets, and the World Bank Group will focus on delivering fintech solutions that enhance financial services, mitigate risks, and achieve stable, inclusive economic growth."

Mrs. Lagarde and Dr. Kim presented the Agenda in a panel discussion today during the Annual Meetings in Bali. They were joined by Sri Mulyani Indrawati, Minister of Finance of Indonesia; Lesetja Kganyago, Governor of the South African Reserve Bank; and Mark Carney, Governor of the Bank of England and Chair of the Financial Stability Board. 
With their near universal membership, the Fund and the Bank, are well positioned to gather information from all countries and to reflect on their respective needs and objectives at various levels of economic and technological development. They both also offer a forum for sharing the experience of countries that are not members of international standard-setting bodies on issues such as combating money laundering and terrorism financing, market integrity, and consumer protection. The Financial Stability Board and several other international standard-setters have been reviewing the implications of fintech developments and have indicated regulation and supervision priorities.

The IMF and World Bank will start developing specific work programs on fintech, as the nature and scope of their members' needs become clearer, in response to the Bali Fintech Agenda. The IMF's initial focus will be on the implications for national and global monetary and financial stability; and the evolution of the International Monetary System and global financial safety net.

In response to the Bali Fintech Agenda, the World Bank will focus on using fintech to deepen financial markets, enhance responsible access to financial services, and improve cross-border payments and remittance transfer systems. The Bank will draw on the International Finance Corporation's growing experience in this area. The Agenda contributes to building the foundations of the digital economy that is a key pillar in the World Bank Group's larger disruptive technologies engagement.

\section{Executive Board Statement}

IMF Executive Directors welcomed the opportunity to consider the Bali Fintech Agenda, and praised the excellent ongoing cooperation between the Fund and World Bank staff in this area, along with other international bodies. Directors broadly endorsed the Agenda as a framework for the consideration of high level fintech issues by individual country members, including in their own domestic policy discussions. They recognized that the Agenda does not represent a work program for the Fund and World Bank Group. Directors concurred that the elements of the Agenda have broad relevance to all member countries and that national authorities should tailor the application of these elements in light of their specific circumstances. This would help reap the benefits of fintech while remaining vigilant about the potential risks and enhancing preparedness to address them. Directors also noted that the elements of the Agenda could apply to both conventional and Islamic financial instruments and products.

While recognizing the rapid pace of fintech development and its uncertain impact, Directors concurred that fintech offers wide ranging possibilities in deepening and enhancing the efficiencies of financial systems, broadening access to financial services - especially in low income countries and for underserved populations - and supporting broader economic 
development and inclusive growth. They acknowledged the potential risks posed by rapid technological changes to financial systems and individual users and stressed the need for adequate preparation and cross agency coordination by national authorities, including through strengthening of institutional capacity, building up knowledge, improving communication with stakeholders, and expanding consumer education. Directors called on the Fund to stand ready to provide technical assistance, particularly for countries with significant capacity gaps, while facilitating information sharing.

Directors generally considered the elements of the Agenda as broadly balanced in pointing out opportunities while acknowledging potential risks of fintech. They agreed on the need to strike the right balance between enabling financial innovation and reinforcing competition and the commitment to open, free and contestable markets on the one hand and addressing challenges to financial integrity, consumer protection, and financial stability on the other.

Directors broadly agreed on the need to augment regulatory and legal frameworks to support the sound development of fintech services and safeguard financial systems. They called for close international cooperation and coordination to address regulatory gaps and prevent the potential risk of a race to the bottom in regulatory compliance, including Anti-Money Laundering/Countering the Financing of Terrorism compliance and the spread of global systemic risks.

Directors called on staff to work closely with the standard setting bodies (SSBs) and relevant international bodies, while avoiding duplication and overlap. They encouraged staff to continuously monitor and analyze fintech developments and consider their implications within the Fund's mandate, focusing on analytical and country work with respect to cross border capital flows, financial integrity, national and global monetary and financial stability, and the evolution of the International Monetary System and global financial safety net.

\section{ANNEX \\ The Bali Fintech Agenda}

I. Embrace the Promise of Fintech with its far-reaching social and economic impact, particularly in low-income countries, small states, and for the underserved, and prepare to capture its possible wide-ranging benefits, including: increasing access to financial services and financial inclusion; deepening financial markets; and improving cross-border payments and remittance transfer systems. Reaping these benefits requires preparation, strengthening of institutional capacity, expanding outreach to stakeholders, and adopting a cross-agency approach involving relevant ministries and agencies.

II.Enable New Technologies to Enhance Financial Service Provision by facilitating foundational infrastructures, fostering their open and affordable access, and ensuring a 
conducive policy environment. Foundational infrastructures include telecommunications, along with digital and financial infrastructures (such as broadband internet, mobile data services, data repositories, and payment and settlement services). The infrastructures should enable efficient data collection, processing, and transmission, which are central in fintech advances.

\section{Reinforce Competition and Commitment to Open, Free, and Contestable}

Markets to ensure a level playing field and to promote innovation, consumer choice, and access to high-quality financial services. The successful and large-scale adoption of technology would be facilitated by an enabling policy framework regardless of the market participant, underlying technology, or method by which the service is provided.

Policymakers should address the risks of market concentration, and should foster standardization, interoperability, and fair-and-transparent access to key infrastructures.

\section{Foster Fintech to Promote Financial Inclusion and Develop Financial Markets}

by overcoming challenges related to reach, customer information, and commercial viability, and by improving infrastructure. The evolving digital economy together with effective supervision are essential in overcoming long-standing barriers to financial inclusion across a broad range of financial services and in enabling developing countries to leverage promising new pathways for economic and financial development to support growth and alleviate poverty. Examples include expanding access to finance while reducing costs, providing new ways to raise funding, enabling new information services to assess risks, and spurring new businesses. To achieve these goals, fintech issues should be part of a national inclusion and financial and digital literacy strategies, while fostering knowledge-sharing between public- and private-sector players, civil society, and other stakeholders.

\section{V.Monitor Developments Closely to Deepen Understanding of Evolving Financial}

Systems to support the formulation of policies that foster the benefits of fintech and mitigate potential risks. The rapid pace of fintech will necessitate improvements and possible extensions in the reach of monitoring frameworks to support public-policy goals and to avoid disruptions to the financial system. Information-sharing and exchange would support improved monitoring. Achieving these objectives brings out the importance of continuous monitoring - including by maintaining an ongoing dialogue with the industry, both innovators and incumbents - to identify emerging opportunities and risks, and to facilitate the timely formation of policy responses.

\section{Adapt Regulatory Framework and Supervisory Practices for Orderly}

Development and Stability of the Financial System and facilitate the safe entry of new products, activities, and intermediaries; sustain trust and confidence; and respond to risks. Many fintech risks might be addressed by existing regulatory frameworks. However, new issues may arise from new firms, products, and activities that lie outside the current regulatory perimeter. This may require the modification and adaptation of regulatory frameworks to contain risks of arbitrage, while recognizing that regulation should remain proportionate to the risks. Holistic policy responses may be needed at the 
national level, building on guidance provided by standard-setting bodies.

VII. Safeguard the Integrity of Financial Systems by identifying, understanding, assessing, and mitigating the risks of criminal misuse of fintech, and by using technologies that strengthen compliance with anti-money laundering and combating the financing of terrorism (AML/CFT) measures. While fintech innovation generally supports legitimate goals, some innovations may enable users to evade current controls for criminal ends, thus posing a threat to financial integrity. Country responses have varied considerably; but, in all cases, it is important to strengthen AML/CFT compliance and monitoring, including by using technology (Regtech and Suptech solutions) to support regulatory compliance and supervision.

VIII. Modernize Legal Frameworks to Provide an Enabling Legal Landscape with greater legal clarity and certainty regarding key aspects of fintech activities. Sound legal frameworks support trust and reliability in financial products and services. This is undermined, however, where legal frameworks fail to keep pace with fintech innovation and evolving global financial markets. An enabling legal framework can be fashioned by having clear and predictable legal rules that accommodate technological change, tailored to national circumstances, particularly in areas such as contracts, data ownership, insolvency, resolution, and payments.

IX. Ensure the Stability of Domestic Monetary and Financial Systems by considering the implications of fintech innovations to central banking services and market structure, while: safeguarding financial stability; expanding, if needed, safety nets; and ensuring effective monetary policy transmission. Fintech could transform the financial markets through which monetary policy actions are transmitted and could challenge the conduct of monetary policy as well as redefine central banks' role as lenders of last resort. On the other hand, fintech could help central banks improve their services, including potentially issuing digital currency, and expanding access to and improving the resilience of payments services.

X. Develop Robust Financial and Data Infrastructure to Sustain Fintech Benefits that are resilient to disruptions - including from cyber-attacks - and that support trust and confidence in the financial system by protecting the integrity of data and financial services. Developing such robust infrastructure raises a broad spectrum of issues that are relevant not only to the financial sector but also to the digital economy at large, including data ownership, protection, and privacy, cybersecurity, operational and concentration risks, and consumer protection.

XI. Encourage International Cooperation and Information-Sharing across the global regulatory community to share knowledge, experience, and best practices to support an effective regulatory framework. As new technologies increasingly operate across borders, international cooperation is essential to ensure effective policy responses to foster opportunities and to limit risks that could arise from divergence in regulatory 
frameworks. Sharing experiences and best practices with the private sector and with the public at large would help catalyze discussion on the most effective regulatory response, considering country circumstances, and to build a global consensus. The IMF and World Bank can help in facilitating the global dialogue and information-sharing.

\section{Enhance Collective Surveillance of the International Monetary and Financial} System and the adaptation and development of policies to support inclusive global growth, poverty alleviation, and international financial stability in an environment of rapid change. Fintech is blurring financial boundaries - both institutionally and geographicallypotentially amplifying interconnectedness, spillovers, and capital flow volatility. These developments could lead to increased multipolarity and interconnectedness of the global financial system, potentially affecting the balance of risks for global financial stability. The IMF and World Bank could help in improving collective surveillance and assist member countries via capacity building, in collaboration with other international bodies. 


\section{THE BALI FINTECH AGENDA—CHAPEAU PAPER}

October 3, 2018

\section{EXECUTIVE SUMMARY}

Rapid advances in financial technology are transforming the economic and financial landscape, offering wide-ranging opportunities while raising potential risks. Fintech can support potential growth and poverty reduction by strengthening financial development, inclusion, and efficiency-but it may pose risks to consumers and investors and, more broadly, to financial stability and integrity.

National authorities are keen to foster fintech's potential benefits and to mitigate its possible risks. Many international and regional groupings are now examining various aspects of fintech, in line with their respective mandates. There have been calls for greater international cooperation and guidance about how to address emerging issues, with some also cautioning against premature policy responses.

In response to these calls from member countries, the IMF and the World Bank staff have developed the Bali Fintech Agenda, summarized in Annex I of this paper. The Agenda brings together and advances key issues for policymakers and the international community to consider as individual countries formulate their policy approaches. It distills these considerations into 12 elements arising from the experiences of member countries. ${ }^{1}$

The Agenda offers a framework for the consideration of high-level issues by individual member countries, including in their own domestic policy discussions. It does not represent the work program of the IMF or the World Bank, nor does it aim to provide specific guidance or policy advice. The Agenda will help guide the focus of IMF and World Bank staff in their work on fintech issues within their expertise and mandate, inform their dialogue with national authorities, and help shape their contributions to the work of the standard-setting bodies and other relevant international institutions on fintech issues. Implications for the work programs of the IMF and World Bank will be developed and presented to their respective Executive Boards for guidance as the nature and scope of the membership's needs--in response to the Bali Fintech Agenda-become clearer.

\footnotetext{
${ }^{1}$ A background paper, which elaborates and supplements the Agenda set out in Annex I, can be found in Attachment I of this Chapeau Paper.
} 


\section{Approved By}

Tobias Adrian, Martin

Muhleisen, and Ross

Leckow (IMF); Akihiko

Nishio and Ceyla

Pazarbasioglu (World Bank)
This Agenda has been prepared by an IMF-World Bank team guided by Aditya Narain, Ross Leckow, Vikram Haksar (IMF), and Alfonso Garcia Mora (World Bank), and comprising: Ghiath Shabsigh, Nigel Jenkinson, Jihad Alwazir, Dirk Jan Grolleman, David Jutrsa, Ashraf Khan, Tanai Khiaonarong, John Kiff, Fabiana Melo, Nobuyasu Sugimoto, and Chris Wilson (MCM); Jess Cheng, Masaru Itatani, Arthur Rossi, Nadine Schwarz, and Natalia Stetsenko (LEG); Celine Rochon, Antoine Bouveret, Patrick Gitton, Manasa Patnam, and Weijia Yao (SPR); Gilles Bauche and Evridiki Tsounta (SEC); Kate Langdon and Olga Stankova (COM); and Erik Feyen, Harish Natarajan, Sharmista Appaya, Ana Carvajal, Kuntay Celik, Lesly Goh, Matthew Saal, and Valeria Salomao (World Bank). Administrative assistance provided by Melissa Wills-Dudich and Natalia Naryshkina.

\section{CONTENTS}

Glossary

INTERNATIONAL CONSIDERATIONS

ROLES OF FUND AND BANK

ISSUES FOR BOARD CONSIDERATION

\section{ANNEX}

I. The Bali Fintech Agenda

\section{ATTACHMENT}




\section{Glossary}

\begin{tabular}{ll} 
AI & Artificial Intelligence \\
AML/CFT & Anti-Money Laundering and Combating the Financing of Terrorism \\
API & Application Programming Interface \\
BCBS & Basel Committee for Banking Supervision \\
CD & Capacity Development \\
CDD & Customer Due Diligence \\
CBDC & Central Bank Digital Currency \\
CGFS & Committee on the Global Financial System \\
CPMI & Committee on Payments and Market Infrastructures \\
DLT & Distributed Ledger Technology \\
FATF & Financial Action Task Force \\
FSB & Financial Stability Board \\
GFSN & Global Financial Safety Net \\
GPFI & Global Partnership for Financial Inclusion \\
IAIS & International Association of Insurance Supervisors \\
IMS & International Monetary System \\
IOSCO & International Organization of Securities Commissions \\
IT & Information Technology \\
KYC & Know-Your-Customer \\
ML/TF & Money Laundering and Terrorist Financing \\
MSME & Micro, Small-, and Medium-Sized Enterprises \\
NPPS & New Payment Products and Services \\
Regtech & Regulatory Technology \\
Suptech & Supervisory Technology \\
SSB & Standard-Setting Body \\
& \\
\hline
\end{tabular}




\section{CONTEXT}

1. Technological change. Rapid advances in digital technology are transforming the economic and financial landscape, creating opportunities and challenges for consumers, financial and nonfinancial firms, service providers, and regulators. These developments are largely led by the private sector and are driven by the forces of global digitization and technological progress that are reshaping many aspects of the world's economies and societies.

2. The membership. Experiences and advances in fintech vary across the membership of the IMF and the World Bank. Emerging and developing economy members have needs and policy concerns related to fintech that may contrast with those in advanced economy members, while not always being represented in the standard-setting bodies (SSBs) in which discussions on these topics are being held. IMF and World Bank member countries have been seeking information, assistance, and advice about the appropriate institutional framework that could allow them to best foster the possibilities provided by fintech. This would help them to improve the efficiency and safety of the financial system and to strengthen financial development and inclusion.

\section{OPPORTUNITIES AND RISKS}

3. Opportunities. Fintech offers wide-ranging opportunities, which national authorities are keen to foster. It holds the promise of reducing costs and frictions, increasing efficiency and competition, narrowing information asymmetry, and broadening access to financial servicesespecially in low-income countries and for underserved populations-although the benefits of technological change may take time to fully materialize. Ongoing innovations and technological advances support broader economic development and inclusive growth, facilitate international payments and remittances, and simplify and strengthen regulatory compliance and supervisory processes.

4. Risks. At the same time, national authorities are concerned about potential risks posed to the financial system and to its customers. As the financial system adapts, concerns arise regarding a range of issues, including: consumer and investor protection; the clarity and consistency of regulatory and legal frameworks, and the potential for regulatory arbitrage and contagion; the adequacy of existing financial safety nets, including lender-of-last-resort functions of central banks; and potential threats to financial integrity. Moreover, the adoption process may also pose transition challenges, and policy vigilance will be needed to make economies resilient and inclusive, so as to capture the full benefits.

5. The challenge. In response, policymaking will need to be nimble, innovative, and cooperative and-importantly-will need to strike the right balance between enabling financial innovation on the one hand and addressing challenges to market and financial integrity, consumer protection, and financial stability on the other. This balance is critical to deliver the welfare benefits 
of financial innovation and avoid stalling the development of fintech with the risk of leaving the underserved behind.

\section{INTERNATIONAL CONSIDERATIONS}

6. International bodies. The Financial Stability Board (FSB), the Bank for International Settlements (BIS), the Basel Committee on Banking Supervision (BCBS), the Committee on Payments and Market Infrastructure (CPMI), the International Organization of Securities Commissions (IOSCO), and the International Association of Insurance Supervisors (IAIS) are all reviewing the implications of fintech developments. They have listed priorities and considerations for regulation and supervision, which provide very useful insights for national authorities. The Financial Action Task Force (FATF) has issued guidance on the application of the Anti-Money Laundering and Combating the Financing of Terrorism (AML/CFT) standard to new payment methods.

7. International cooperation. There have been calls for greater international coordination, and fintech is on the agenda of many international and regional groupings. Cooperation is taking shape, including through the exchange of information and discussions of good practices. But so far there has been no framework that looks at the various issues regarding fintech in a holistic way. Such a framework could facilitate further cooperation between the industry and regulators of finance, technology, and competition, within countries and across borders. This would help create an international enabling environment to foster fintech opportunities, while mitigating risks of regulatory arbitrage and potential inconsistencies in the cross-border application of laws and regulations.

\section{ROLES OF FUND AND BANK}

8. Bali Fintech Agenda. In response to these calls from the IMF and World Bank membership, the IMF and World Bank staff have prepared an Agenda, summarized in Annex I. The Agenda outlines high-level issues for consideration by individual country members of the IMF and World Bank as they seek to develop their policy responses to fintech considering the Bretton Woods institutions' near-universal membership and comparative competencies. The Agenda is focused on the implications for the financial sector. It has been prepared to highlight the opportunities and potential risks of fintech, and has benefited from the work by international SSBs and national authorities. A separate background paper in Attachment I elaborates and expands the individual elements of the Agenda summarized in Annex I.

9. Reach. The overarching elements of the Agenda have broad relevance to all member countries. Their application, however, should be tailored to national circumstances and should recognize that the approach to fintech might vary depending on the financial services considered (e.g., credit, savings, insurance, and payments). This will help members reap the benefits of fintech while remaining vigilant about the potential risks and enhancing preparedness to address them. 
10. Next steps. The Agenda does not represent a work program of the IMF and World Bank, nor does it aim to provide specific guidance or policy advice. The Agenda seeks to offer a useful framing of the issues to support further learning and ongoing work. In this context, the staff propose the following next steps:

- The Bali Fintech Agenda will be endorsed by the Executive Boards of both the IMF and the World Bank as a framework for the consideration of high-level issues by individual country members, including in their own domestic policy discussions.

- The IMF and World Bank will continue to closely monitor and analyze fintech developments and their implications. They will reflect on this Agenda in their work within their respective mandates.

- For the IMF, the initial focus will be on the implications of fintech for cross-border capital flows; national and global monetary and financial stability; and the evolution of the International Monetary System and global financial safety net.

- For the World Bank, the initial focus will be on, inter alia, enabling reforms and capacity building to adopt fintech solutions to deepen financial markets, to enhance responsible access to financial services, and to improve cross-border payments and remittance transfer systems. The World Bank will draw on the International Finance Corporation's growing experience in this space. The Fintech agenda contributes to building the foundations of the digital economy that is a key pillar in the World Bank Group's larger disruptive technologies engagement.

- The staff will work closely with all relevant international bodies, including the SSBs as they develop regulatory standards for fintech. As these standards and best practices take shape, the staff will incorporate them into the IMF and World Bank surveillance and capacity development work.

- Implications for the work programs of the IMF and World Bank will be developed and presented to their respective Executive Boards for guidance as the nature and scope of their membership's needs -in response to the Bali Fintech Agenda-become clearer.

\section{ISSUES FOR BOARD CONSIDERATION}

11. Given the above:

a. Do Directors endorse the Bali Fintech Agenda, summarized in Annex I, as a framework for consideration of high-level issues by individual country members, including in their own domestic policy discussions? 


\section{WORLD BANK GROUP}

\section{Annex I. The Bali Fintech Agenda}

Rapid advances in financial technology (fintech) ${ }^{1}$ are transforming the economic and financial landscape, offering wide-ranging opportunities while raising potential risks. Fintech can support potential growth and poverty reduction by strengthening financial development, inclusion, and efficiency-but it may pose risks to financial stability and integrity, as well as to consumer and investor protection. To foster the benefits and to mitigate its possible risks, it is important that financial systems are resilient to technological change without impeding the process of structural transformation, innovation, and competition that it engenders.

Many international and regional bodies are examining the various aspects of fintech, in line with their respective mandates. The IMF and World Bank, in response to calls from member countries for greater international cooperation and guidance about how to address the emerging issues, have developed the "Bali Fintech Agenda." It brings together key considerations for policymakers and the international community into the 12 elements presented below. These considerations apply to both conventional and Islamic financial instruments and products. The Agenda does not represent the work programs of the IMF or the World Bank, nor does it aim to provide specific guidance or policy advice. It is intended as a framework to support awareness, further learning, and ongoing work. As international standards and best practices take shape, they will be incorporated into the work of the IMF and World Bank.

I. Embrace the Promise of Fintech with its far-reaching social and economic impact, particularly in low-income countries, small states, and for the underserved, and prepare to capture its possible wide-ranging benefits, including: increasing access to financial services and financial inclusion; deepening financial markets; and improving cross-border payments and remittance transfer systems. Reaping these benefits requires preparation, strengthening of institutional capacity, expanding outreach to stakeholders, and adopting a cross-agency approach involving relevant ministries and agencies.

II. Enable New Technologies to Enhance Financial Service Provision by facilitating foundational infrastructures, fostering their open and affordable access, and ensuring a conducive policy environment. Foundational infrastructures include telecommunications, along with digital and financial infrastructures (such as broadband internet, mobile data services, data repositories, and payment and settlement services). The infrastructures should enable efficient data collection, processing, and transmission, which are central in fintech advances.

\footnotetext{
${ }^{1}$ Different definitions of fintech have been used by international bodies and national authorities. Drawing on these, this paper adopts a broad interpretation of fintech to describe the advances in technology that have the potential to transform the provision of financial services spurring the development of new business models, applications, processes, and products. A broad definition is adopted to support the high-level considerations of the Agenda, while recognizing that there are differences in the opportunities and risks raised by different technological advances.
} 
III. Reinforce Competition and Commitment to Open, Free, and Contestable Markets to ensure a level playing field and to promote innovation, consumer choice, and access to high-quality financial services. The successful and large-scale adoption of technology would be facilitated by an enabling policy framework regardless of the market participant, underlying technology, or method by which the service is provided. Policymakers should address the risks of market concentration, and should foster standardization, interoperability, and fair-and-transparent access to key infrastructures.

IV. Foster Fintech to Promote Financial Inclusion and Develop Financial Markets by overcoming challenges related to reach, customer information, and commercial viability, and by improving infrastructure. The evolving digital economy together with effective supervision are essential in overcoming long-standing barriers to financial inclusion across a broad range of financial services and in enabling developing countries to leverage promising new pathways for economic and financial development to support growth and alleviate poverty. Examples include expanding access to finance while reducing costs, providing new ways to raise funding, enabling new information services to assess risks, and spurring new businesses. To achieve these goals, fintech issues should be part of a national inclusion and financial and digital literacy strategies, while fostering knowledge-sharing between public- and private-sector players, civil society, and other stakeholders.

\section{Monitor Developments Closely to Deepen Understanding of Evolving Financial Systems to} support the formulation of policies that foster the benefits of fintech and mitigate potential risks. The rapid pace of fintech will necessitate improvements and possible extensions in the reach of monitoring frameworks to support public-policy goals and to avoid disruptions to the financial system. Information-sharing and exchange would support improved monitoring. Achieving these objectives brings out the importance of continuous monitoring-including by maintaining an ongoing dialogue with the industry, both innovators and incumbents-to identify emerging opportunities and risks, and to facilitate the timely formation of policy responses.

\section{Adapt Regulatory Framework and Supervisory Practices for Orderly Development and} Stability of the Financial System and facilitate the safe entry of new products, activities, and intermediaries; sustain trust and confidence; and respond to risks. Many fintech risks might be addressed by existing regulatory frameworks. However, new issues may arise from new firms, products, and activities that lie outside the current regulatory perimeter. This may require the modification and adaptation of regulatory frameworks to contain risks of arbitrage, while recognizing that regulation should remain proportionate to the risks. Holistic policy responses may be needed at the national level, building on guidance provided by standard-setting bodies.

VII. Safeguard the Integrity of Financial Systems by identifying, understanding, assessing, and mitigating the risks of criminal misuse of fintech, and by using technologies that strengthen compliance with anti-money laundering and combating the financing of terrorism (AML/CFT) measures. While fintech innovation generally supports legitimate goals, some innovations may enable users to evade current controls for criminal ends, thus posing a threat to financial integrity. Country responses have varied considerably; but, in all cases, it is important to strengthen AML/CFT compliance and monitoring, including by using technology (Regtech and Suptech solutions) to support regulatory compliance and supervision. 
VIII. Modernize Legal Frameworks to Provide an Enabling Legal Landscape with greater legal clarity and certainty regarding key aspects of fintech activities. Sound legal frameworks support trust and reliability in financial products and services. This is undermined, however, where legal frameworks fail to keep pace with fintech innovation and evolving global financial markets. An enabling legal framework can be fashioned by having clear and predictable legal rules that accommodate technological change, tailored to national circumstances, particularly in areas such as contracts, data ownership, insolvency, resolution, and payments.

IX. Ensure the Stability of Domestic Monetary and Financial Systems by considering the implications of fintech innovations to central banking services and market structure, while: safeguarding financial stability; expanding, if needed, safety nets; and ensuring effective monetary policy transmission. Fintech could transform the financial markets through which monetary policy actions are transmitted and could challenge the conduct of monetary policy as well as redefine central banks' role as lenders of last resort. On the other hand, fintech could help central banks improve their services, including potentially issuing digital currency, and expanding access to and improving the resilience of payments services.

\section{Develop Robust Financial and Data Infrastructure to Sustain Fintech Benefits that are} resilient to disruptions-including from cyber-attacks-and that support trust and confidence in the financial system by protecting the integrity of data and financial services. Developing such robust infrastructure raises a broad spectrum of issues that are relevant not only to the financial sector but also to the digital economy at large, including data ownership, protection, and privacy, cybersecurity, operational and concentration risks, and consumer protection.

XI. Encourage International Cooperation and Information-Sharing across the global regulatory community to share knowledge, experience, and best practices to support an effective regulatory framework. As new technologies increasingly operate across borders, international cooperation is essential to ensure effective policy responses to foster opportunities and to limit risks that could arise from divergence in regulatory frameworks. Sharing experiences and best practices with the private sector and with the public at large would help catalyze discussion on the most effective regulatory response, considering country circumstances, and to build a global consensus. The IMF and World Bank can help in facilitating the global dialogue and information-sharing.

\section{Enhance Collective Surveillance of the International Monetary and Financial System and} the adaptation and development of policies to support inclusive global growth, poverty alleviation, and international financial stability in an environment of rapid change. Fintech is blurring financial boundaries - both institutionally and geographically — potentially amplifying interconnectedness, spillovers, and capital flow volatility. These developments could lead to increased multipolarity and interconnectedness of the global financial system, potentially affecting the balance of risks for global financial stability. The IMF and World Bank could help in improving collective surveillance and assist member countries via capacity building, in collaboration with other international bodies. 


\section{Attachment I. The Bali Fintech Agenda-Background Paper}

\section{EXECUTIVE SUMMARY}

Rapid advances in technology are transforming the economic and financial landscape, offering wide-ranging opportunities while raising potential risks. Fintech can support potential growth and poverty reduction by strengthening financial development, inclusion, and efficiency-but it may pose risks to financial stability and integrity, as well as to consumer and investor protection. National authorities are keen to foster the benefits and mitigate potential risks. Many international and regional bodies are examining the various aspects of fintech, in line with their respective mandates. There have been calls for greater international cooperation and guidance on how to address the emerging issues.

In response to calls from member countries the IMF and World Bank have developed the "Bali Fintech Agenda." It brings together key considerations for policymakers and the international community into 12 elements arising from the experience of member countries, including:

I. Embrace the promise of fintech.

II. Enable new technologies to enhance financial service provision.

III. Reinforce competition and commitment to open, free, and contestable markets.

IV. Foster fintech to promote financial inclusion and develop financial markets.

V. Monitor developments closely to deepen understanding of evolving financial systems.

VI. Adapt regulatory framework and supervisory practices for orderly development and stability of the financial system.

VII. Safeguard the integrity of financial systems.

VIII. Modernize legal frameworks to provide an enabling legal landscape.

IX. Ensure the stability of domestic monetary and financial systems.

$X$. Develop robust financial and data infrastructure to sustain fintech benefits.

$\mathrm{XI}$. Encourage international cooperation and information-sharing.

XII. Enhance collective surveillance of the international monetary and financial system.

The Agenda does not represent the work program of the IMF or the World Bank, nor does it aim to provide specific guidance or policy advice at this stage. It will help guide the focus of IMF and World Bank staff in their work on fintech issues within their expertise and mandate, inform their dialogue with national authorities, and help shape their contributions to the work of the standard-setting bodies (SSBs) and other relevant international institutions on fintech issues. 


\section{CONTENTS}

ELEMENTS OF THE BALI FINTECH AGENDA $\underline{15}$

I. Embrace the Promise of Fintech 15

II. Enable New Technologies to Enhance Financial Service Provision $\underline{15}$

III. Reinforce Competition and Commitment to Open, Free, and Contestable Markets $\underline{17}$

IV. Foster Fintech to Promote Financial Inclusion and Develop Financial Markets $\underline{18}$

V. Monitor Developments Closely to Deepen Understanding of Evolving Financial Systems $\underline{21}$

VI. Adapt Regulatory Framework and Supervisory Practices $\underline{22}$

VII. Safeguard Financial Integrity $\underline{24}$

VIII.Modernize Legal Frameworks to Provide an Enabling Legal Landscape $\underline{25}$

IX. Ensure the Stability of Domestic Monetary and Financial Systems $\underline{27}$

X. Develop Robust Financial and Data Infrastructure to Sustain Fintech Benefits $\underline{28}$

$\mathrm{XI}$. Encourage International Cooperation and Information-Sharing $\underline{30}$

XII. Enhance Collective Surveillance of the International Monetary and Financial System $\underline{31}$

\section{TABLE}

1. Fintech Reports by Select International Forums and Standard-Setting Bodies $\underline{34}$ 


\section{INTRODUCTION}

\section{Rapid advances in digital technology are transforming the economic and financial} landscape, creating opportunities and challenges for consumers, financial and nonfinancial firms, service providers, and regulators. These developments are largely led by the private sector and are driven by the forces of global digitization and technological progress that are reshaping many aspects of the world's economies, governments, and societies. Experiences and advances in fintech are varied across the memberships of the IMF and the World Bank, which include emerging and developing economies, as well as small and fragile states where needs and policy developments related to fintech contrast with those in advanced economies. Besides, they may not always be represented in the SSBs in which such discussions are being held. ${ }^{1}$ In response, policymaking will need to be nimble, innovative, and cooperative. Importantly, it will need to strike the right balance between enabling financial innovation and addressing challenges to financial stability, market and financial integrity, and consumer protection. This balance is critical to deliver the welfare benefits of fintech and avoid stalling the development of fintech with the risk of leaving the underserved behind.

\section{IMF and World Bank member countries have been seeking information, assistance,} and advice on the appropriate institutional framework that can allow them to best foster the possibilities provided by fintech to improve the efficiency and safety of the financial system and to deepen financial inclusion. ${ }^{2}$ The IMF and World Bank have been closely monitoring and analyzing fintech developments and their implications within their respective mandates. This paper has been prepared by IMF and World Bank staff, to highlight the opportunities and potential risks of fintech, and has benefited from the work by international bodies and national authorities. ${ }^{3}$

\section{Technology and finance have long had a symbiotic relationship. Advancements in} information and computer technologies and shifts in the expectations of technology-savvy customers are blurring traditional boundaries among intermediaries, markets, and new service providers-potentially leading to increased decentralization, introducing new products and concepts, and affecting barriers to entry. Some fintech applications, like mobile money, have been tested and tried over the past decade in many emerging and developing countries, and provide a wealth of useful experience on how even simple technologies can aid large-scale financial inclusion and development.

\footnotetext{
${ }^{1}$ Different definitions of fintech have been used by international bodies and national authorities. Drawing on these, this paper adopts a broad interpretation of fintech to describe the advances in technology that have the potential to transform the provision of financial services spurring the development of new business models, applications, processes, and products. A broad definition is adopted to support the high-level considerations of the Agenda, while recognizing that there are differences in the opportunities and risks raised by different technological advances.

${ }^{2}$ Financial inclusion means that individuals and businesses have access to useful and affordable financial products and services that meet their needs (transactions, payments, savings, credit, and insurance), and are delivered in a responsible and sustainable way.

${ }^{3}$ See Table I for a summary of fintech reports by select international forums and SSBs.
} 
4. Fintech offers wide-ranging possibilities, which national authorities are keen to foster. It holds the promise of reducing costs and frictions, increasing efficiency and competition, narrowing information asymmetry, and broadening access to financial services-especially in low-income countries and for underserved populations-although the benefits of technological change may take time to fully materialize. Ongoing innovations and technological trends can be fostered by the financial sector to support broader economic development and inclusive growth, facilitating international payments and remittances, and simplifying and strengthening compliance and supervisory processes. Some authorities are exploring new regulatory approaches (such as sandboxes, incubators, accelerators, and innovation hubs) that allow for experimentation, innovation, and information exchange while aiming to understand how to better manage associated risks.

5. At the same time, national authorities are concerned about potential risks posed to the financial system and to its customers. For example, concerns have been raised over the price volatility of traded crypto-assets, threats to consumer and investor protections, and the potential for regulatory arbitrage and contagion-both within jurisdictions and across borders. Concerns have also been raised over the adequacy of existing financial safety nets, including lender-of-last-resort functions of central banks. Furthermore, the new features of emerging technologies and business models can make it challenging to ensure clarity and consistency of legal and regulatory frameworks within countries and across borders. Importantly, managing cyber risks becomes a vital element of overall operational resilience, especially as greater technological interconnections among financial firms, infrastructure, service providers, and consumers allows for greater access to financial networks through multiple points of entry. Finally, notwithstanding fintech's benefits, the adoption process may also pose transition challenges, and policy vigilance will be needed to make economies resilient and inclusive.

\section{National authorities are also concerned about the potential threat to financial} integrity. Some fintech applications raise new risks of criminal activity. In particular, new payment methods may be used to evade existing controls and to commit such crimes as money laundering, fraud, and terrorist financing. At the same time, some technological innovations can strengthen financial integrity, for example, by facilitating compliance with existing AML/CFT requirements such as customer due diligence (CDD) (e.g., digital IDs) and by assisting regulators (e.g., software solutions to strengthen risk-based AML/CFT supervision). Moreover, robust information technology (IT) security frameworks will reduce opportunities for cyber fraud and other related criminal activities.

7. International bodies have kept a close watch on fintech developments. The FSB, the $B C B S$, the CPMI, the IOSCO, and the IAIS have all looked at the implications of fintech developments and listed priorities and considerations for regulation and supervision, which provide very useful insights for national authorities. The FATF has issued guidance on the application of the AML/CFT standard to new payment methods. 
8. There have been calls for greater international coordination. Meanwhile, cooperation is taking shape (for instance, through bilateral fintech Memoranda of Understanding between regulatory agencies), and fintech is on the agenda of many international and regional groupings. This has led to some exchange of information and to discussions of good practices; but there is a need for a more coordinated approach that brings together the industry and regulators of finance, technology, and competition, within countries and across borders. This would help create an international enabling environment to foster fintech opportunities, while mitigating the risks of regulatory arbitrage and potential contradictions in the cross-border application of laws and regulations.

9. This agenda is a response to these calls from the IMF and World Bank membership, and outlines high-level considerations for policymakers and the international community. Recognizing that fintech is a new and fast-moving area, the Agenda is focused on the implications of fintech for the financial sector, considering the IMF's and World Bank's near-universal membership and each institution's comparative competencies. Its overarching elements have broad relevance to all member countries and relevant international bodies, but those elements should be tailored to national circumstances, as well as recognizing that the approach to fintech might vary depending on the financial services being considered (e.g., credit, savings, insurance, and payments). This will help members reap the benefits of fintech while remaining vigilant about the potential risks and enhancing preparedness to address them.

10. The Agenda discusses issues for consideration by the membership on fintech and does not represent the work program of the IMF or the World Bank, nor does it aim to provide specific guidance or policy advice. The Agenda seeks to offer a useful framing of the issues to support further learning and ongoing work. The considerations in the Agenda apply to both conventional and Islamic financial instruments and products. The IMF and World Bank will reflect on this Agenda in their work within their respective mandates. In particular, the IMF, through its surveillance and CD work, will focus on the implications of fintech for cross-border capital flows; national and global monetary and financial stability; the evolution of the international monetary system (IMS); and the global financial safety net (GFSN). For the World Bank, the initial focus will be on, inter alia, enabling reforms and capacity building to adopt fintech solutions to deepen financial markets, to enhance responsible access to financial services, and to improve cross-border payments and remittance transfer systems. The Bank will draw on the International Finance Corporation's growing experience in this space. The Fintech agenda contributes to building the foundations of the digital economy that is a key pillar in the World Bank Group's larger disruptive-technologies engagement. The staff will work closely with all relevant international bodies, including through our participation in the relevant SSBs, as they develop regulatory standards for fintech. As these standards and best practices are developed by the SSBs, the staff will incorporate them into the work of the IMF and World Bank. 


\section{ELEMENTS OF THE BALI FINTECH AGENDA}

\section{Embrace the Promise of Fintech}

Welcome the current rapid advancements in fintech, with its far-reaching social and economic impact, and undertake preparations to capture its potentially wide-ranging benefits.

\section{Fintech can significantly influence and enhance the provision of financial services} worldwide, particularly in low-income countries and for the underserved. Innovation in financial services is not a new phenomenon. However, the speed, intensity, and broad consequences throughout societies across the globe make these developments of a different nature. Rapidly increasing computing power; innovations in cryptography, data aggregation, and management; distributed computing; Artificial Intelligence (Al); and the penetration of smart phones and other mobile devices are all part of the foundation for potentially far-reaching changes in the financial sector.

12. This evolution of the financial system should be welcomed. Fintech developments are introducing new business models, new service providers, and products, thus offering opportunities for major efficiency gains that have the potential to spur widespread economic and social benefits, particularly in low-income countries. Governments are exploring fintech from the perspective of increasing financial inclusion for underserved populations and deepening financial markets, and of improving the efficiency of financial service provision. Fintech offers wide-ranging opportunities to, for example: improve cross-border payments systems, including the transfer of worker remittances; help financial institutions to streamline their business processes; and improve access to financial services, particularly for MSMEs.

13. Reaping the full benefits of fintech requires adequate preparation. This includes the timely strengthening of institutional capacity, recruiting relevant expertise, building up knowledge, improving external communication with stakeholders, and expanding consumer education. A crossagency approach, including relevant ministries and agencies (such as central banks and financial regulators, telecommunication authorities, competition authorities, consumer protection agencies, Financial Intelligence Units, and internal revenue agencies) will support consistency of policies and objectives.

\section{Enable New Technologies to Enhance Financial Service Provision}

Enable the development and adoption of fintech by developing foundational infrastructures, and by fostering their open and affordable access and ensuring a conducive policy environment.

\section{Investing in supporting infrastructure has been a key feature of successful fintech} adoption around the world. The defining characteristics of fintech services include: intensive use of digital channels for customer interactions; customer choice about when and how they transact and interact with the service providers; and smooth and seamless use of services. The factors enabling 
such services include foundational physical, telecommunications, and financial infrastructures, as well as the overall policy and regulatory environment. The foundational digital infrastructure includes among other factors, broadband internet, mobile data services, access to critical data repositories, digital ID infrastructure, and digital payment services.

\section{The collection and processing of data, in an automated manner, has been a key feature}

of advances in fintech. Fintech services collect data from customers using their applications, as well as accessing customers' transactional accounts held with financial institutions. Automating data gathering reduces the scope of error and fraud, particularly when the data are accessed directly from the relevant data custodian, and allows for a faster response while strengthening CDD and appraisal processes.

\section{A range of actions can be considered to develop open and affordable digital and financial infrastructures, and a conducive policy environment for fintech:}

a. Facilitate the development of telecommunications, broadband, and mobile data services-including in rural areas-and the achievement of sustainable universal access. Attention should be paid to ensuring a basic quality of service and affordability across customer segments.

b. Promote digitization across the government and more broadly the entire economy, and enable financial sector's fair access to relevant data. This access should be based upon appropriate safeguards and should be provided in a safe and sound manner under a robust data protection, governance, and privacy framework, to ensure data quality and to guard against introducing any biases through the intensified use of data and data analytics.

c. Encourage the development of digital ID mechanisms to reliably authenticate customers remotely. In doing so, authorities should guard against risks of financial exclusion due to such factors as digital illiteracy. The digital ID mechanisms should be underpinned by robust processes to reliably link a real person uniquely to the ID.

d. Encourage the development of financial infrastructures, such as those for credit reporting and cross-border payments, that have fair, transparent, and risk-based access and usage criteria. ${ }^{4}$ For cross-border payments, approaches like regional payment systems, enabling new models that reduce layers of intermediaries, and access to domestic payments systems for new entrants should be considered.

\footnotetext{
4 The terms "fair," "transparent," and "risk-based" are commonly referred to by SSBs and have been adopted in relevant standards, such as the CPMI-IOSCO Principles for Financial Market Infrastructures.
} 


\section{Reinforce Competition and Commitment to Open, Free, and Contestable}

\section{Markets}

Reinforce fair competition and commit to open, free, and contestable markets to ensure a level playing field, and to promote innovation, consumer choice, and access to quality financial services.

17. Fintech could lower barriers to entry and act as a potent driver for competition, market contestability, and innovation by narrowing information asymmetries, reducing operational and compliance costs, and improving efficiencies. This would promote consumer choice and improve access to quality financial services, which is particularly important for underserved households and firms. The adoption of novel technologies has been a common occurrence in the financial sector, and fintech has the capacity to affect activities and interactions along the entire financial value chain; in some cases, with profound implications for competition.

\section{Traditional business models and distribution channels-from the back office to the} customer relationship-are being revisited because of the unbundling and creation of services, the emergence of new service providers, the changing role of incumbents, and demanding consumers empowered by technology. Fintech is eroding the boundaries among financial products, services, and markets and inducing a shift in the composition of the industry and the competitive landscape. ${ }^{5}$

19. Fintech may produce network effects and economies of scale and scope. Some fintech services—such as peer-to-peer lending platforms and distributed ledger technology (DLT) applications, including crypto-assets and asset tokenization, and smart contracts-may change the role of some intermediaries or make them redundant. Many incumbent financial institutions are adopting fintech approaches and establishing new partnerships to compete with new market entrants, established tech companies, and telecommunication providers. The growing abundance of consumer data - as well as rapid advances in data storage, processing, connectivity capabilities, and information and communication infrastructures-are all key factors behind the above-mentioned market dynamics.

\section{To reap the benefits of fintech, a lasting commitment to level the playing field in} terms of access to data, technologies, and infrastructures is important. At present, incumbents largely control access to such critical financial infrastructures as payment and credit reporting systems, collateral registries, and central securities depositories; while technology and communication companies control access to services like communications, data services, e-commerce portals, social media platforms, and search engines. Third-party providers that offer ancillary services, such as cloud computing and analytics, that underpin many fintech services are reducing the need for large investments by start-ups and are lowering barriers to entry.

\footnotetext{
${ }^{5}$ For example, data aggregators and open Application Programming Interfaces (APIs) are unbundling financial services (e.g., delinking payments from a traditional bank account), improving product transparency, and lowering switching costs.
} 


\section{Considerations for promoting fair competition and open markets include:}

a. Leveraging fintech capacity to lower barriers to entry for nontraditional players, including through promoting the proportionate, flexible, consistent, and predictable application of laws and regulations, while maintaining competition and market contestability.

b. Applying competition policies to address risks of market concentration and abuse by both entrants and incumbents. Reinforce fair competition and innovation as explicit technology-neutral policy objectives for the financial sector, and apply them in a transparent manner.

c. Adapting competition policy frameworks for fintech, taking into account new business models.

d. Developing approaches for similar treatment of similar activities and risks in a proportionate manner to provide a level playing field regardless of the market participant, underlying technology, or method by which the service is provided.

e. Fostering standardization, interoperability, and fair and transparent access to key infrastructures. Given the centrality of data and information exchange for fintech, developing a balanced framework for access to data and data infrastructures can help lower barriers to entry, including through common standards and open technology platforms. This will facilitate the flow of information and connectivity between services and platforms, both existing and new - a factor that undergirds fintech innovation and market contestability. These issues are critical in both domestic and cross-border contexts. For example, cross-border payment services are essential for trade flows, remittances, migration, and e-commerce, although they are often inefficient and expensive, and some correspondent banks have reduced their provision of such services. The process of setting standards should be inclusive, and its procedures should be transparent and well communicated.

\section{Foster Fintech to Promote Financial Inclusion and Develop Financial Markets}

Foster fintech to promote financial inclusion by overcoming challenges related to reach, customer information, and commercial viability and to develop markets by improving infrastructure and depth.

\section{Access to finance is an important determinant of inclusive growth in developing} countries. ${ }^{6}$ Yet currently, an estimated 1.7 billion adults globally do not have access to the formal financial economy. This is caused by such market frictions as geographical barriers to access,

\footnotetext{
${ }^{6}$ More broadly, the Sustainable Development Goals have embedded commitments to financial inclusion through specific targets and related indicators.
} 
absence of collateral, the high opportunity cost of holding cash, and market failures. While gains have already been achieved in promoting inclusion, the fast-evolving digital economy together with effective supervision are essential to overcome the hurdles to the achievement of broader financial inclusion.

\section{Fintech will be critical to overcoming longstanding barriers to financial inclusion and to providing an opportunity for developing countries to leapfrog straight to digital approaches:}

a. Reach. Limited physical infrastructure has been one of the most important barriers to access across a wide range of financial products. Digital channels deployed by banks, telecom companies, and other providers have enabled millions of people with mobile phones to access digital finance over recent years and have connected them to not just payment services but also to savings, insurance, investment, and credit. Moreover, mobile money has enabled access to essential services like water and electricity through pay-as-you-go services.

b. Customer information. Financial service providers require customer verification as part of CDD processes and risk underwriting and management. Digital identity and data footprints from the use of digital services (including mobile networks, electronic payments, e-commerce, and social media) provide the customer information necessary to open accounts, enabling access to a range of financial products and services.

c. Commercial viability. Inclusion of unserved and underserved populations implies providing a high volume of low-value payments, deposits, insurance, and lending products, tailored to customers' needs. Doing so sustainably requires making sufficient returns to cover costs without setting prices beyond reach. That requires a low cost of providing services, which can be achieved with automation and straight-through processing using fintech solutions.

\section{Fintech offers such benefits as expanding access, reducing costs, and increasing}

transaction convenience. New entrants and new business models are generating newer ways to onboard, distribute, and service financial products that are better tailored to unbanked populations. Moreover, technology solutions can help overcome some of the barriers faced by women in accessing finance, enhancing their financial resilience, and enabling better occupational choice. Digital ID has enabled financial institutions in some jurisdictions to reduce the costs of onboarding customers and has allowed governments to reliably target benefits and distribute them digitally. Fintech services like mobile money have already demonstrated their potential. Looking ahead, alternative lending platforms and big data have the potential to enable access to credit for MSMEs and individuals. In addition, technologies like APIs and DLT can enable the development of new modes of recording and sharing data across agricultural and business value chains, thereby reducing information asymmetries. 
25. Fintech can also support broader financial-sector development. Fintech is opening the door to new mechanisms for companies, including MSMEs, to raise funding directly from investors, such as crowdfunding and market-placed lending. In tandem, it is supporting the development of key information services that allow investors to assess the risks of their investments, such as creditscoring mechanisms. It is also creating new channels for the distribution of capital markets products-such as mutual-fund supermarkets-enhancing competition in currently bank-dominated distribution networks, and potentially offering more and better investment choices to investors while reducing costs. At the same time, it is allowing customers to access other support servicessuch as investment advice-at a lower cost. Such platforms and services are also being used in the context of insurance and retirement products, expanding choices for consumers.

\section{To encourage the adoption of fintech to promote financial inclusion and develop financial markets, a number of actions could be considered:}

a. Embed fintech topics in national inclusion and financial literacy strategies and consider establishing a dedicated body to track fintech development, promote the ease of doing business in the sector, and consider international cooperation opportunities.

b. Promote educational efforts and avoid a gap between the "haves" and the "have nots." Create fintech awareness by educating individuals and MSMEs about key developments, including risks, and provide them with the tools to make an informed decision. Several countries have started integrating digital literacy into financial literacy initiatives and have started combining them with specific programs that reach the target population segments.

c. Foster partnerships and promote knowledge-sharing and knowledge-exchange among public- and private-sector players, civil society, and other key stakeholders in the fintech ecosystem. Some countries are establishing a forum for public- and private-sector players to jointly explore leveraging fintech for financial inclusion; in other countries, existing cooperative forums are being used. Some countries have also been actively involved in the creation of fintech hubs or labs to support the application of technology in financial services. Some financial regulators also have dedicated fintech offices as a "one-stop shop" to assist them in navigating the regulatory landscape.

d. Move toward digitized government payments. This will enhance trust and improve account penetration and payments efficiency for underserved segments of the population. Coupled with digital ID, this may also reduce fraud and tax evasion. Several countries have taken a deliberate approach to shift all benefit transfers to digital means and have required government agencies to accept digital payments for government services and revenue collection. 


\section{Monitor Developments Closely to Deepen Understanding of Evolving} Financial Systems

Monitor developments closely to support the formulation of policies that foster the benefits of fintech and mitigate potential risks.

\section{The rapid pace of fintech will necessitate improvements in monitoring frameworks.}

New risks and opportunities may be difficult to monitor using current frameworks, which do not collect information from market entrants and do not cover new financial products and activities. Creating new avenues and forums for dialogue and experience-sharing, with both incumbent firms and entrants in the fintech industry, would help authorities in gathering useful information to support timely public-policy interventions that can address obstacles to innovation. Moreover, challenges to monitoring stem from the automation of financial activity and the anonymity of transactions.

\section{Extension of monitoring frameworks may be needed to support public-policy goals.}

New opportunities may warrant a public-policy response to capture the full benefits. Data-gathering and surveillance should be aimed at supporting public-policy goals relating to fair and orderly markets, financial inclusion, and the promotion of competition as well as to financial stability risk, consumer and investor protection, and financial integrity. This may necessitate the extension of current reporting powers to enable authorities to collect the required information from new market participants and on new products and activities. In addition, active engagement with participants in the fast-changing financial markets would provide intelligence that would help authorities reshape their monitoring approaches and policies.

29. Flexible monitoring frameworks, including automating the collection and analysis of data, will help authorities keep pace with fintech developments. This would call for continuous assessment of the changing industry landscape, participants, business models, interconnectedness, and risk concentrations. While it may be possible to draw on current frameworks that apply to regulated entities and activities in the short run, that would require an agile approach, including flexibility in reporting populations. Technological advancements can support the automation and analysis of data and can facilitate monitoring.

30. Information-sharing and exchange would support improved monitoring. There may be considerable benefits from a greater exchange of information and experience internationally, given the increasingly cross-border nature of many fintech innovations, products, and services. Such an exchange would facilitate global monitoring of financial stability risks and broader public-policy objectives, such as financial integrity.

\section{The following elements could aid authorities in enhancing monitoring frameworks:}

a. Scope: A framework to support effective system-wide oversight needs to provide a broad view of new activities and entities, of the opportunities that they present, and of the risks 
that they pose. Such a framework would facilitate an understanding of changes in market structure and the identification and analysis of risks to key policy objectives.

b. Information-collection powers: Enhancements to data-collection powers may be needed to support an extension of the data-reporting perimeter to include new entities (e.g., requiring basic information through registration) and the collection of information on new products and activities.

c. Flexibility in monitoring: This is important to capture innovation and changes in intermediation that could lead to potential opportunities and risks. Collection of market intelligence on developments and trends may provide a valuable supplement to formal data collection.

d. Process: An effective monitoring framework would support the identification and assessment of developments and risks on a regular and continuous basis.

e. Jurisdiction-specific features: Monitoring should be tailored to the specific characteristics of domestic financial markets, their regulatory framework, and their international connections.

\section{Adapt Regulatory Framework and Supervisory Practices for Orderly Development and Stability of the Financial System}

Adapt the regulatory framework and supervisory practices to facilitate the safe entry of new products, activities, and intermediaries; to sustain trust and confidence; to maintain financial stability; and to be responsive to potential risks.

32. Regulatory certainty helps support beneficial financial innovation. As the financial system evolves, it is important that the regulatory framework continue to provide trust, confidence, and a supporting environment for innovation. Providing additional regulatory clarity supports the safe entry of new products, activities, and intermediaries, and reduces regulatory uncertainty and the potential loss of confidence by consumers and investors linked to unsound practices and fraud.

\section{Existing regulatory approaches may need to be supplemented to address fintech-} driven changes in the financial landscape. Implementing the internationally agreed standards on financial sector supervision and regulation (such as the Basel Core Principles of Banking Supervision) is a necessary foundation for strong financial systems, which in turn are better equipped to facilitate the safe entry of new fintech products and players. Although existing legislation (e.g., on fraud and consumer protection) typically also applies to new products and firms, there is merit in reviewing and, where necessary, modifying frameworks for financial regulation, and adapting supervisory approaches to ensure that they facilitate safe entry and safeguard the appropriate use of innovative technologies. Similarly, while fundamental principles of corporate governance-including independent audit, client asset segregation, adequate financial resources, and disclosure-are also 
generally applicable to new providers and services, there may be a need to bolster and-where necessary-embed such principles in regulations to address the risks from rapid financial innovation.

\section{Changes in the financial landscape could result in financial stability risks and business} and market conduct issues as well as opportunities for regulatory arbitrage. The need for the introduction or adaptation of regulation should be assessed based on the identification of market failures and externalities that bring risk to financial stability or that lead to excessive regulatory arbitrage. Modification of the regulatory perimeter may be required to avoid arbitrage and to ensure that activities are appropriately and evenly regulated independent of the service provider and that risks to financial stability are contained through appropriate policy interventions. Effective financial regulation may also require broader cooperation domestically (e.g., drawing on data protection, competition, telecommunication, central banks, and other authorities) and internationally, given the inherent cross-border nature of many innovations.

\section{Regulation of new activities and innovative business models should be proportionate} to their risks, in order not to stifle innovation. The application of proportionate regulatory, governance, and disclosure requirements may help support innovation while mitigating the risks. For example, authorities may facilitate safe market entry by introducing temporarily restricted authorization schemes for new market entrants, where specific regulatory requirements are eased according to the perceived risks (such as sandboxes to support testing and piloting), and by introducing restricted licensing schemes. At the same time, authorities may need to consider to what extent existing outsourcing frameworks and data-privacy regulations are technology-neutral or will need to be revised to allow for technological developments (e.g., cloud computing).

\section{Technological advances may support the effectiveness and efficiency of regulation.}

The increasing use of advanced technology (e.g., machine learning, automated data collection supported by enhanced Legal Entity Identifiers, and big data analysis) by authorities and by financial institutions demonstrates the potential for improvements in both the efficiency and effectiveness of regulatory and supervisory functions and in improving risk management and compliance by firms. Further enhancements such as machine-readable regulations are under discussion. However, there are also attendant issues that must be managed, including: (a) data quality, standardization, and volume bring operational challenges; (b) over-reliance on quantifiable signals and risks may result in misguided decisions; (c) homogeneity of approaches and models may increase procyclicality; and (d) the potential of misuse of fintech to circumvent regulatory requirements.

\section{Keeping up with market developments may be challenging for regulatory authorities.}

Authorities will need to ensure that the knowledge, skills, and tools of staff remain relevant and effective to supervise innovative business models. That could entail additional training as well as the recruitment of additional specialized staff to complement existing expertise. Strong international supervisory cooperation will facilitate knowledge transfer and the sharing of international best practice.

\section{Countries should formulate a holistic policy response, building on guidance provided}

by SSBs. This could entail a review of the adequacy of the regulatory framework and perimeter, 
informed by assessments of financial stability risks, misconduct, and operational resilience (including cybersecurity). Such reviews could draw on the expertise of all relevant authorities. If modifications in the regulatory framework are needed, the following aspects should be considered:

a. Regulation should be technology-neutral and designed to target externalities and financial stability risks, misconduct, and consumer protection. Regulation should support competition and should facilitate financial inclusion and broader financial market development.

b. Regulation should be proportionate and adaptable, while seeking international consistency to avoid cross-border arbitrage.

c. The potential use of fintech solutions by both firms and supervisors should be explored.

d. Current staffing and training models should be assessed and additional specialized skills may be needed.

\section{Safeguard Financial Integrity}

Safeguard the integrity of financial systems by identifying, understanding, assessing, and mitigating the fintech-related risks of criminal misuse, and by using technologies that strengthen compliance with AML/CFT measures.

\section{Money Laundering and Terrorist Financing (ML/TF), as well as related underlying} crimes, may significantly undermine a country's economic and financial stability. It is therefore paramount that countries implement sound AML/CFT frameworks in an effective way, in line with the FATF 40 Recommendations.

40. Some fintech applications pose new threats to financial integrity. While they generally support legitimate goals, some new business models or products are also used to criminal ends. The potential risks vary greatly from one product to another, but crypto-assets are typically deemed to present a higher potential of misuse for $\mathrm{ML} / \mathrm{TF}$, fraud (including cyber fraud), tax evasion, and other illicit activities. Their decentralized nature and global reach, as well as the absence of a regulated intermediary in many transactions raises difficult questions about whom to regulate. Their varying degrees of anonymity or "pseudo-anonymity" can significantly impede regulatory action. The increased complexity of transaction models could further constrain the authorities' ability to identify the real beneficial owners of assets and potential criminal activity.

\section{In response to these challenges, national authorities have taken a variety of}

approaches. Some jurisdictions have refrained from taking action while monitoring developments and potential ML/TF risks. Other have adapted their existing AML/CFT framework. Others still have banned all or part of specific activities deemed more at risk, such as "initial coin offerings." 
42. The international community-particularly through the FATF-has taken important steps to respond to the challenges posed by fintech but more may be needed. Pursuant to the FATF standard, countries should take steps to mitigate their ML/TF risks-including those stemming from fintech-related activities and products. The FATF's work has focused on "new payment products and services" (e.g., prepaid cards, mobile payments, internet-based payment services) and "virtual currencies" (or crypto-assets). The FATF has notably issued guidance to countries on the application of the FATF standard to "virtual currencies," recommending that AML/CFT efforts focus on the points of intersection between the crypto-asset world and the traditional financial sector-in particular, the crypto-asset exchanges. This may involve requiring exchanges to apply "preventive measures" (e.g., CDD, suspicious transaction reporting). As the use of crypto-assets becomes more widespread and the need to "cash out" of crypto-assets diminishes, it may also be necessary to regulate other service providers that operate entirely within the crypto space (e.g., certain types of wallet providers) for AML/CFT purposes. Further FATF work is continuing.

\section{Regulatory technology (Regtech and Suptech) solutions could facilitate and} strengthen AML/CFT compliance. Identity verification technology (including biometrics) may provide effective and secure ways to confirm identity. Blockchain applications may be used to build a know-your-customer (KYC) repository accessible to multiple users. Data analytics tools can support continuous risk-monitoring and the identification of suspicious transactions patterns.

\section{Actions to address the financial integrity risks could include:}

a. Identify, understand, and assess the ML/TF risks, and apply AML/CFT measures commensurate with these risks. An in-depth understanding of the potential opportunities for misuse is a prerequisite to effective mitigation. In line with FATF recommendations, the response-from both regulators and reporting entities-should be proportionate to the identified risks and to the circumstances of the country.

b. Identify and encourage the use of fintech products and services that strengthen the AML/CFT framework.

c. Develop institutional capacity and ensure adequate communication with fintech providers. A regular dialogue with fintech developers and providers greatly facilitates capacity building within the competent authorities and raises the private sector's awareness to the risks and AML/CFT obligations.

\section{Modernize Legal Frameworks to Provide an Enabling Legal Landscape}

Modernize legal frameworks to provide an enabling landscape with greater legal clarity and certainty regarding key aspects of fintech activities, as well as to remove unnecessary legal obstacles.

45. Sound legal frameworks support the evolution of the financial system by providing a foundation of stability, clarity, and predictability. Legal certainty helps build confidence in the trustworthiness and reliability of financial products and services. However, legal certainty may be 
undermined where legal frameworks fail to keep pace with evolving global financial markets, with the shift to new technology-driven business models, and with the move away from traditional financial intermediaries. Existing legal frameworks may also be inadequately equipped to manage new risks arising from greater reliance on highly complex technologies, such as automated processes and decentralized protocols, and activities that increasingly blur jurisdictional borders.

46. It may be necessary to consider whether broad-based legal principles call for some refinement to remain a suitable foundation for the modern global financial landscape. For example, greater legal certainty may be called for with respect to the formation, validity, and enforcement of contracts or signatures executed through technological means, such as electronic signatures and automated processes like "smart contracts." Separately, countries may also wish to examine the suitability of existing laws that govern ownership of data ${ }^{7}$ and insolvency and bankruptcy. ${ }^{8}$

\section{Modernizing the legal framework may also entail supplementing gaps and clarifying} ambiguities in their legal principles specific to fintech activities. Such modernization would involve building on the specific features of the country's legal framework, as well as the industry and social practices facilitated by fintech. One area for consideration relates to non-traditional account arrangements that underpin the movement of funds between peer-to-peer transaction counterparties. ${ }^{9}$ Legal uncertainty as to the treatment of balances held under such arrangements, particularly under insolvency law, can introduce unintended and unmanageable risks. This legal uncertainty is exacerbated by fintech developments that rely on and drive further usage of these non-traditional commercial arrangements, such as certain automated payment solutions and algorithms that coordinate transaction execution (e.g., "validators" and "notaries"). Similar instances of uncertainty may arise with respect to the legal principles governing settlement finality (with particular attention to local insolvency law that may unexpectedly void a settlement that was thought to be final), including in a blockchain setting.

\section{An enabling legal framework requires the support of predictable legal principles and} greater harmonization across jurisdictions. Legal certainty and predictability would be enhanced by more closely harmonized legal approaches across jurisdictions to key issues in such areas as

\footnotetext{
${ }^{7}$ For example, if there is ambiguity or inconsistency as to whether ownership of derived data resides with the owner of the underlying data or the party that created the derived data, particularly as financial services become increasingly "unbundled" and new business models emerge.

${ }^{8}$ For example, if there is uncertainty as to how crypto-asset balances would be characterized: as property, as a general creditor claim, or in some other category.

${ }^{9}$ For example, special deposit account arrangements where a third party merely holds and releases funds, conditioned upon an agreed-upon event.
} 
payments law ${ }^{10}$ as well as data usage, privacy, and security. ${ }^{11}$ This calls for a consistent but flexible approach, recognizing the diversity of legal frameworks and legal tools across different jurisdictions.

\section{Ensure the Stability of Domestic Monetary and Financial Systems}

Explore applications of fintech innovations to central banking services, while safeguarding financial stability, expanding if needed safety nets and ensuring effective monetary policy transmission.

\section{Rapid fintech developments are reshaping financial markets and their structures.}

Fintech is progressively blurring the boundaries between intermediaries and markets, as well as between digital service providers moving into the financial space, nonbank financial companies, and banks. These developments could affect central banks' capacity to implement monetary policy and the ability of supervisory agencies to safeguard financial stability, raising both challenges and opportunities.

\section{The potential impact of fintech on monetary transmission and the effectiveness of} policy needs further consideration. In many countries, monetary policy is transmitted by changing the marginal price of liquidity_central bank reserves-available to large commercial banks, which in turn is transmitted to lending and deposits rates, as well as inducing a repricing of bonds, the exchange rate, and other assets. Fintech innovations can change any segment of this transmission. The balance-sheet channel could be affected by how households and firms react to new financial products or delivery methods, while the bank-lending channel could be reshaped by changes in the composition of bank financing. Fintech may alter the risk-taking behavior of both bank and nonbank intermediaries with implication for monetary transmission. Fintech could also affect the role of banks in payments, and could thus affect their need for central bank liquidity. Policymakers will need to think through the impact of specific fintech innovations, and-if necessary-adapt operational frameworks of monetary policy to ensure effective transmission.

\section{Fintech offers central banks the opportunity to explore new services, while having to} consider new risks:

a. Some central banks are considering the possibility of issuing "central bank digital currency" (CBDC) reflecting such issues as the rapid decline of cash use in their systems, maintaining demand for central bank money, reducing the cost of maintaining printed cash, and improving financial inclusion by reducing transaction costs. The design of CBDCs by central banks could have implications for the sources of commercial bank funding in the future, an issue that would call for careful examination.

\footnotetext{
${ }^{10}$ For example, by harmonizing legal terminology and treatment, such as whether decentralized blockchain-based settlement frameworks constitute "funds-transfer systems."

${ }^{11}$ For example, through greater legal consistency as to the limits and validity of data-related agreements that would remove unnecessary costs to managing complex global data flows.
} 
b. Some central banks are exploring new fintech applications to improve and expand access to payments systems. Applications, such as DLT, are being examined closely to ascertain their capacity to increase the efficiency and resilience of payments systems.

c. Safeguarding financial stability could increasingly become a challenge. Fintech could impact the nature of systemic risks. For example, fintech-enabled multiple payment systems could improve the resilience of payments flows and reduce counterparty risk, but could also become conduits amplifying risks at times of stress. Similarly, the determination of what constitutes a systemically important entity, from a stability perspective, may need to be expanded not only to a wider set of nonbank financial institutions but also, possibly, to entities providing critical fintech infrastructure.

d. Central bank support and the role of the "lender of last resort" in times of crisis might need to be re-examined. Fintech activities could lead to a decentralization and shift of activities outside the perimeter of the traditional banking sector. Although such shifts are not a new phenomenon, the speed and intensity with which these developments take place raise issues for central banks, financial supervisors, and other agencies to consider-including any potential need for adjustments to their legislative and regulatory frameworks may be needed.

e. Implications for other financial safety net arrangements might need to be considered as well. This could include analysis of the nature of "deposit" insurance, as well as its scope and coverage, and issues relating to crisis management and resolution of systemic fintech firms.

\section{Develop Robust Financial and Data Infrastructure to Sustain Fintech Benefits}

Develop robust digital infrastructure that is resilient to disruption and that supports trust and confidence in the financial system by protecting the integrity of data and financial services.

\section{Robust financial and data infrastructure is necessary to provide operational resilience} and to preserve confidence. Strong standards of operational resilience help market participants and infrastructures to withstand and rapidly recover from disruptions, thus supporting confidence in the continuity of services and preserving the "safety and soundness" and the integrity of the financial system.

\section{Fintech innovation increases IT dependencies and operational risks that should be} carefully managed. Effective governance structures and risk-management processes are important to identify and manage risks associated with the use of fintech. The greater reliance on such technologies leads to new operational risks and more interdependencies among service providers (financial institutions, technology providers, and others) that may threaten the operational resilience of financial and data infrastructures. Financial institutions are increasingly partnering with or 
outsourcing operational support for technology-based financial services to third-party service providers. In such cases, the associated risks for those operations and delivery of the financial services remain with incumbents. As many third-party providers fall outside the regulatory perimeter, increased emphasis on managing operational risks and ensuring robust outsourcing arrangements is key to preserving financial stability.

54. Economies of scale may increase concentration risks. Economies of scale may motivate greater consolidation among financial firms or third-party service providers, increasing interconnectedness, and accentuating the potential for concentration and network risk. The provision of key infrastructure services by one or a few dominant players raises risks (both domestic and cross-border) that would need to be carefully managed and addressed by information-sharing, cooperation, and macroprudential policies as needed.

55. Cybersecurity is paramount. Cybersecurity is a vital element of overall operational resilience, recognizing that financial services infrastructures are only as strong as the weakest link. Increased digitalization of finance encouraged by financial innovation places even more pressure on the importance of strong cybersecurity. It is thus important that cybersecurity be fully integrated into the development of new processes from the start. Robust standards are needed to achieve a minimum level of cyber resilience across the entire financial services supply chain to maintain the safety and soundness of the financial system and integrity of data.

56. Robust business continuity and recovery plans are essential. A key component of strong resilience is the ability to withstand and rapidly recover from operational disruption. This necessitates robust back-up systems, incident response plans, and arrangements that are regularly tested with realistic failure scenarios.

\section{The increased digitalization of finance increases the need for strong frameworks to} protect individual and institutional data. As more entities gain access to large volumes of personal and proprietary data, efforts to gain improper access to this information will increase. Robust data governance frameworks are essential to sustain the trust and confidence of users and to deliver the benefits of fintech. Important components of such frameworks include: (i) clarity of data ownership; (ii) safeguards to protect data confidentiality, availability and integrity, while encouraging appropriate regulatory information-sharing; (iii) privacy considerations; and (iv) the ethical use of data. Processes will be needed to ensure that data controllers and processors implement effective data protection mechanisms and retain accountability for data breaches.

\section{The following steps may be helpful for authorities to strengthen operational resilience:}

a. Encourage financial firms and technology providers to embed cybersecurity and operational risk management into an enterprise-wide risk-management framework and to promote technical standards on cyber and information security. Build upon industry standards issued by SSBs to set expectations for operational risk management and governance that include monitoring of compliance with applicable regulatory requirements when introducing new products. 
b. Promote robust outsourcing arrangements that address technology dependence and apply strong disaster-recovery and business-continuity principles and standards for digital infrastructure. Market players should have robust processes for due diligence, risk management, and monitoring of any operation outsourced to a third party. Contracts should outline the responsibilities of each party, agreed service levels and audit rights.

c. Monitor and manage domestic and cross-border concentration risk, because economies of scale could lead to large financial or technology firms becoming increasingly important in the provision of key infrastructure services, thus increasing vulnerability to systemic disruption.

d. Ensure that robust data-governance frameworks are in place to address issues of data ownership, privacy, confidentiality, integrity, availability, and the ethical use of data. Priorities are the protection of consumer and institutional data and the integrity of the financial services industry infrastructure.

e. Additional capacity and specialized skills may be needed to supervise operational and cybersecurity risks.

\section{Encourage International Cooperation and Information-Sharing}

Encourage strong international cooperation across the global regulatory community to share information, experience and best practices, to support an effective regulatory framework.

59. As new technologies increasingly operate across borders, international cooperation is essential to ensure effective regulation, aiming to foster opportunities and to limit risks that could arise from divergence in regulatory frameworks. Heterogeneity across the international community could result in activity migration toward more lightly regulated jurisdictions in a "race to the bottom" that would undermine regulation at the national level. Greater harmonization between national regulatory frameworks would help level the playing field and facilitate the adoption of innovative technologies in financial services on a global scale.

\section{Sharing experience and best practices would help provide guidance on the most} effective regulatory frameworks, considering country circumstances. Institutions with universal membership, such as the IMF and the World Bank, are well-positioned to gather information from all countries and to reflect on the needs and objectives of members at various levels of economic and technological development. A global approach is already undertaken by international standard setters in some specific areas, including AML/CFT, market integrity, and consumer protection. 


\section{Countries can support international collaboration, leveraging their membership in international financial institutions including the IMF, the World Bank, and SSBs by:}

a. Sharing views and experiences with each other and with the private sector on fintech developments and country responses using international fora as conduits. Building experience and capacity, and contributing to influence the global agenda.

b. Monitoring the increased interconnectedness of financial systems, both domestically and internationally, sharing information, and enhancing communication across countries.

c. Standing ready to adapt policy responses to reflect evolution and adaptation of the financial system (e.g., consumer-protection risks, risks of financial exclusion, systemic risk and financial stability issues including those arising from capital flows).

d. Monitoring global market developments and emerging issues and risks, including opportunities and challenges to financial development and inclusion, and disruptions to market structures and to business models of existing financial service providers, to ensure the adequacy of the regulatory environment.

e. Building technical and regulatory capacities by participating in international training and peer-learning programs.

\section{Enhance Collective Surveillance of the International Monetary and Financial System}

Enhance collective surveillance of the financial sector, and the adaptation and development of policies to support inclusive global growth, poverty alleviation, and international financial stability in an environment of rapid change.

62. Promoting inclusive growth, access to financial services, and financial stability are key global policy objectives supported by international bodies. In the face of rapid technological change, including in the provision of financial services, a key challenge will be to strengthen bilateral and multilateral policy advice provided by the IMF and the World Bank in support of these objectives, especially given their likely domestic and cross-border impacts. Country policy experience is limited and policy positions are gradually being developed, with at times different policy approaches being taken. This presents an important opportunity to share knowledge and experience and to sustain policy collaboration on identifying fintech opportunities, as well as to manage emerging spillovers and systemic risks.

\section{Fintech innovations could change the landscape for cross-border savings and} transactions-affecting both capital and current-account flows by offering new ways to save and lend, by allowing for faster and cheaper services, and potentially by reducing the cost of compliance with cross-border regulations. There is a need to identify, monitor, and assess any changes to the nature, magnitude, and structure of resulting capital flows. Fintech services could potentially amplify 
interconnectedness, spillovers, and capital-flow volatility; alter the relative attractiveness of currencies; and reduce the effectiveness of capital-flow measures. More generally, fintech may facilitate data collection for surveillance but could pose challenges due to anonymity and the increasingly decentralized nature of payments.

64. The growing blurring of boundaries - whether institutional or locational-for the origin and destination of international flows will require closer examination. The IMF's Institutional View on the liberalization and management of capital flows provides a basis for consistent advice on policies related to capital flows. It will continue to apply regardless of technological changes. However, fintech innovations-including the growing use of crypto-assetsmay increase the complexity of assessing the drivers of capital flows, diminish the effectiveness of purely domestic policy responses, and hence increase the value of cross-border cooperation of policies to mitigate the riskiness of capital flows.

65. Fintech developments could have implications for the future shape of the IMS. A firstorder change would be the emergence of a more decentralized and interconnected global financial system, with a key unknown being whether such a system would be more or be less resilient to shocks. More broadly, the emergence of a new range of digital assets, including potentially those issued by central banks, could accelerate the transition to a more multipolar global economy and create uncertainties over the evolution of international currency transactions and liquidity.

66. The implications of fintech developments for the global financial safety net (GFSN) also merits deeper review. If changes to the balance of risks for global financial stability arise, implications for the GFSN will also need to be examined. Moreover, if the trend to a more multipolar international currency system were to materialize, that could have implications for the development of a wider range of reserve assets and reserve pooling mechanisms.

67. There is significant scope to help member countries via capacity building and other means by the IMF and the World Bank, in collaboration with other international bodies. The range of issues affected by fintech includes financial development, inclusion, stability, integrity, and regulation, as well as consumer and investor protection. A key instrument is the joint IMF-World Bank Financial Sector Assessment Program (FSAP), which assesses and makes recommendations on: the development and resilience of the financial sector; the quality of the legal, regulatory, and supervisory framework; the state of financial inclusion; and the capacity to manage and resolve financial crises. FSAP recommendations are incorporated in the capacity development $(C D)$ and other activities of the IMF and the World Bank, as appropriate. Such efforts are already being undertaken for cybersecurity.

68. Examples of actions by the IMF, the World Bank, and other global bodies to enhance collective and bilateral surveillance, the assessment of financial sector developments and risks, and the implementation of emerging best practices in an environment of rapid change include: 
a. Filling data and statistics gaps to strengthen risk monitoring in a global economic environment subject to an increased pace of technological progress.

b. Supporting efforts to strengthen financial integrity and resilience, including through policy advice, assessments of countries' AML/CFT frameworks, and CD activities.

c. Providing CD and bilateral policy advice, and financial solutions to country authorities to help them strengthen their legal, regulatory, and supervisory frameworks consistent with the IMF and World Bank mandates, including frameworks governing central banking and financial regulation, insolvency, payments and security settlement systems, taxation, and financial development and inclusion for both households and firms, and consumer and investor protection.

d. Advising on the management of potential risks to public-sector balance sheets (e.g., financial contingent liabilities) and analyzing the effectiveness of macroprudential policies in mitigating new systemic risks, via bilateral and multilateral surveillance work.

e. Strengthening CD activities related to technological and financial innovations including cybersecurity, benefiting from strategic partnerships with donor countries.

f. Assessing the implications of fintech for capital flows and the nature of cross-border spillovers and related policies, including the pace and sequencing of capital-flow liberalization to preserve the collective gains from openness, consistent with the IMF's Institutional View, and World Bank practice.

g. Assessing the implications of fintech for the IMS to support its effective operation in the context of rapid innovations affecting both the domestic and global economies (e.g., disruptions to barriers to entry and network effects in cross-border payments), with a focus on such issues as exchange rate adjustment, reserve accumulation, and global rebalancing.

h. Maintaining a strong and effective GFSN, including regional financing arrangements, focused on countries' needs and geared toward minimizing global imbalances, and preventing contagion, while reflecting the potential impact of fintech on volatility, volume, and composition of flows, and new channels of cross-payments systems.

i. Proactively coordinating to address global risks and opportunities. Fostering more effective supervision and credible cross-border resolution frameworks. Strengthening policies and economic fundamentals through more effective bilateral and multilateral surveillance (e.g., using new technologies such as Al, machine learning, and big data analytics in surveillance) and policy collaboration on spillovers and systemic risks. Helping countries enhance crisis preparedness to risks from new forms of disruptive flows. 
Financial Stability Board

The June 2017 Report "Financial Stability Implications from Fintech Technology" analyzes the potential financial stability implications from fintech with a view toward identifying supervisory and regulatory issues that merit authorities' attention. It identifies 10 areas, of which 3 are seen as priorities for international collaboration: (a) managing operational risk from third-party service providers; (b) mitigating cyber risks; and (c) monitoring macrofinancial risks that could emerge as fintech activities increase. Other recent work on fintech includes (a) the November 2017 report "Artificial Intelligence and Machine Learning in Financial Services," which considers the financial stability implications of the growing use of artificial intelligence (AI) and machine learning in financial services; (b) the May 2017 report "Fintech Credit: Market Structure, Business Models and Financial Stability Implications" authored in collaboration with the Committee on the Global Financial System (CGFS), which highlights the implications for financial stability should fintech credit grow to account for a significant share of overall credit. Potential benefits include access to alternative funding sources for borrowers, a lower concentration of credit in the traditional banking system and pressure on incumbent banks to be more efficient in their credit provision. Systemic risk concerns may arise, such as weaker lending standards and more procyclical credit provision in the economy. Fintech credit also poses challenges to the regulatory perimeter and authorities' monitoring of credit activity; and (c) the October 2017 "Summary Report on Financial Sector Cybersecurity Regulations, Guidance and Supervisory Practices," which presents conclusions from a stock take on cybersecurity regulations, guidance and supervisory practices.

\section{Basel Committee on Banking Supervision}

The February 2018 "Sound Practices on the Implications of Fintech Developments for Banks and Bank Supervisors" assesses how "fintech" may affect the banking industry and the activities of supervisors in the near to medium term. Various future potential scenarios are considered, with their specific risks and opportunities. Current observations suggest that the rapid adoption of enabling technologies and emergence of new business models pose an increasing challenge to incumbent banks in almost all the banking industry scenarios considered. The Report lays out 10 key "implications and observations" on supervisory issues. Earlier work by the BCBS relevant to fintech which remain current includes (a) the June 2011 "Principles for the Sound Management of Operational Risk" which describe 11 principles of sound operational risk management covering 3 main areas: governance; the risk management environment; and the role of disclosure; (b) the February 2005 "Outsourcing in Financial Services," which builds upon the high-level principles on outsourcing developed by the Joint Forum to highlight how the rapid rate of IT innovation, along with an increasing reliance on external service providers have the potential of leading to systemic problems unless appropriately constrained by a combination of market and regulatory influences; and (c) the July 2003 "Risk Management Principles for Electronic Banking" which identify 14 principles to help banking institutions expand their existing risk oversight policies and processes to cover their e-banking activities. 


\section{International Organization of Securities Commissions}

The February 2017 "Research Report on Financial Technology" highlights the increasingly important intersection between fintech and securities market regulation, describes the impact it has on investors and financial services, and analyzes both the opportunities and risks that each of these new technologies presents to investors, securities markets and their regulators. Other recent work includes: (a) the December 2016 "Update to the Report on the IOSCO Automated Advice Tools Survey," which concludes that the continued development of automated investment-advice tools requires ongoing monitoring to help regulators understand its impact on the provision of investment advice to retail clients. It also includes an overview of the regulatory measures and guidance adopted by some survey respondents, (b) December 2015 "Mechanisms for Trading Venues to Effectively Manage Electronic Trading Risks and Plans for Business Continuity," which explores the measures that trading venues use to address the risks posed by extreme volatility. The report finds that these mechanisms can be an effective way for trading venues to mitigate the effects of extreme volatility and preserve orderly trading, (c) the April 2013 "Technological Challenges to Effective Market Surveillance: Issues and Regulatory Tools," which sets forth a number of questions for consultation and outlines proposed recommendations to assist Market Authorities in addressing the challenges posed with respect to improving surveillance capabilities on a cross-market and cross-asset basis and making more useful to Market Authorities the data collected for surveillance purposes, (d) the October 2011 "Regulatory Issues Raised by the Impact of Technological Changes on Market Integrity and Efficiency" makes four recommendations that seek to promote market liquidity and efficiency, price transparency, and investors' execution quality in a fragmented environment. It identifies possible outstanding issues and risks posed by existing or developing market structures and it describes how these risks should be addressed, and (e) the July 2009 "Principles on Outsourcing by Markets," which sets out the factors that market operators should consider when deciding whether, and to whom, to outsource processes, services, or functions and are also designed to assist market authorities in their oversight of these arrangements

\section{International Association of Insurance Supervisors}

The February 2017 "Fintech Developments in the Insurance Industry" report highlights the potential impact of fintech on insurance-sector competitiveness, consumer choice, interconnectedness, business-model viability, and regulatory oversight. The report also examines the challenges and opportunities that insurance supervisors face in a rapidly changing insurance environment. It analyses the potential impact of fintech based on three scenarios: Incumbents successfully maintaining the customer relationship; the fragmentation of the insurance value chain with incumbents no longer in control; and big technology firms squeezing out traditional insurers.

\section{Financial Action Task Force}

FATF, the standard-setter for AML/CFT, has been actively following developments in NPPS, and, more recently, in the fintech space. It has notably been monitoring the ML/TF trends and typologies that new products and activities may present, and has issued guidance on the implementation of the AML/CFT standard with respect to NPPS and fintech. The FATF has expressed its strong support for responsible 
financial innovation in line with the AML/CFT standard. Engagement with the fintech and Regtech Community is one of its priorities and the FATF has organized a number of roundtables, meetings and fora involving representatives from this community, to develop a constructive dialogue. Its recent and relevant reports, standards and guidance includes (a) International Standards on Combating Money Laundering and the Financing of Terrorism \& Proliferation-the FATF Recommendations; (b) Guidance for a Risk-Based Approach to Prepaid Cards, Mobile Payments and Internet-Based Payment Services, June 2013; (c) Virtual Currencies_Key Definitions and Potential AML/CFT Risks (preliminary assessment of the ML/TF risks that virtual currency payment products and services may present), June 2014: and (d)_Guidance for a Risk-Based Approach to Virtual Currencies, June 2015.

\section{Committee on Payments and Market Infrastructures (CPMI)}

The March 2018 "Central Bank Digital Currencies" report with Markets Committee looks at two types of central bank digital currency: a wholesale currency limited to select financial institutions, and a general-purpose currency accessible to the public. The report analyses the implications of both types in three core central banking areas: payments, monetary policy implementation, and financial stability. The February 2018 "Cross-Border Retail Payments" report aims to provide a holistic view of cross-border retail payments and a broader understanding of general issues and challenges in the cross-border retail payments market. It also discusses a number of alternatives emerging to the established correspondent banking model including interconnecting domestic payment infrastructures; expansion of "closed-loop" proprietary systems across borders; and "peer-to-peer" mechanisms based on DLT. It acknowledges that these alternatives are mostly still nascent, and it remains to be seen if they can provide viable solutions to bring across-the-board improvement. The February 2017 "Distributed Ledger Technology in Payment, Clearing and Settlement_-an Analytical Framework" exhorts central banks and other authorities to weigh the risks of using blockchain and other distributed ledger technology (DLT) in payment, clearing, and settlement against potential cost and efficiency savings offered by the technology. The report focuses on the implications of the technology for efficiency and safety and for the broader financial market. It contains a set of key questions that may be useful to authorities and others to consider when looking at DLT arrangements. The November 2015 "Digital Currencies" discusses the factors that are potentially relevant for the development and use of digital currencies and distributed ledgers; and considers the possible implications-risks and opportunitiesof interest to central banks arising from these innovations and recommends that central banks continue monitoring and analyzing the implications of these developments.

\section{G20/Global Partnership for Financial Inclusion}

The 2016 "G20 High-Level Principles for Digital Financial Inclusion" views digital financial services, together with effective supervision (which may be digitally enabled), as essential to closing the remaining gaps in financial inclusion. Building upon the $2010 \mathrm{G} 20$ Principles for Innovative Financial Inclusion, they lay out eight principles that provide a basis for country action plans reflecting country context and national circumstances to leverage the huge potential offered by digital technologies to enhance financial inclusion. 